\title{
Eksplorasi Teknik Membuat Ragam, Finishing dan Joining Bambu sebagai Kombinasi Material Produk Tas Wanita
}

\author{
Andega Cantika Laarasati dan Bambang Tristiyono \\ Departemen Desain Produk, Fakultas Arsitektur Desain dan Perencanaan, \\ Institut Teknologi Sepuluh Nopember (ITS) \\ e-mail: gacombi@prodes.its.ac.id
}

\begin{abstract}
Abstrak-Indonesia merupakan salah satu negara yang memperoleh devisa melalui ekspor bambu dan terus mengalami kenaikan yang signifikan. Kondisi ini memperlihatkan potensi Indonesia sebagai salah satu produsen bambu terbesar di dunia serta meningkatkan peluang pasar untuk material bambu maupun produk bambu. Tingginya minat pasar terhadap produk kerajinan tangan termasuk kerajinan tangan dengan material bambu membuat industri pengolahan bambu semakin berkembang. Pengembangan produk bambu yang selama ini dilakukan sebagian besar adalah untuk furniture, appliance dan home decor. Padahal produk bambu memiliki potensi untuk dikembangkan sebagai produk fashion. Terlebih industri mode menjadi salah satu penyumbang terbesar dalam perekonomian sektor industri kreatif di Indonesia. Berdaasarkan latar belakang dan fenomena di atas, penelitian ini membahas tentang perancangan produk apparel dari bambu. Sebagai langkah awal dilakukan observasi dan deep interview pada salah satu pengrajin bambu yang sudah memiliki pengalaman lebih dari 10 tahun di Sentra pengrajin sangkar burung Selaawi, Garut, Jawa Barat serta produsen bambu yang ada di Bandung untuk mengetahui karakteristik bambu, teknik pengolahan, treatment dan finishing pada material bambu. Studi perlakuan material dilakukan dengan eksperimen yaitu eksplorasi bentuk dengan mengkombinasikan teknik-teknik pengolahan bambu, eksplorasi sambungan antara material bambu dengan kombinasi material dan eksplorasi pewarnaan khusus untuk bambu. Hasil akhir dari eksplorasi ini diharapkan dapat diterapkan pada desain produk fashion tas wanita dengan aksesori pendukung dari material bambu.
\end{abstract}

Kata Kunci-Eksplorasi Bambu, Kerajinan Tangan, Fashion Apparel.

\section{PENDAHULUAN}

I NDONESIA merupakan salah satu negara yang menghasilkan produksi bambu cukup besar. Dari aspek sosial dan ekonomi, tanaman bambu yang telah merata di daerah-daerah pedesaan dan dapat dikatakan merupakan tanaman yang merakyat telah mampu mengangkat perekonomian masyarakat sebagai penghasilan yang utama atau tambahan [1]. Produksi material bambu juga memberikan kontribusi pada peningkatan devisa negara [2]. Karateristik utama dari kemajuan globalisasi adalah munculnya peluang pasar baru yang terbuka pada produsen kerajinan tangan [3]. Tingginya minat pasar terhadap produk kerajinan tangan termasuk kerajinan tangan dengan material bambu membuat semakin berkembangnya industri pengolahan bambu untuk menambah nilai ekonomi dari bambu. Industri tersebut mulai dari skala industri rumah tangga, kecil hingga menengah.
Pengolahan bambu untuk aneka produk kerajinan termasuk mebel masih mayoritas yaitu $60 \%$, sedangkan untuk tujuan aneka tali, anyaman dan konstruksi sekitar 40\% [4]. Ada berbagai jenis pengolahan bambu untuk berbagai produk kearajinan termasuk furniture, tali, anyaman dan konstruksi, serta produk-produk fashion. Didukung dengan perkembangan industri mode telah menjadi salah satu kontributor terbesar bagi perekonomian di Indonesia di mana sektor kreatif saat ini mengalami peningkatan yang cukup baik.

Berdasarkan hal tersebut, mengeksplorasi material bambu dengan beraneka ragam perlakuan terhadap material merupakan hal yang penting dilakukan, sebagai cara untuk memahami karateristik material agar mendapat tampilan visual serta fungsi yang paling optimal. Dengan mengeksplorasi material bambu sebagai produk apparel dengan jenis tas yang akan dikombinasi dengan material lain, hal ini akan menambah referensi desain untuk pengrajin bambu lokal, sehingga secara tidak langsung dapat membantu pelestarian kebudayaan dan serta peningkatan pembelian terhadap produk kerajinan tangan dari Indonesia.

\section{KAJIAN PUSTAKA}

Industri kreatif adalah industri yang berasal dari pemanfaatan kreativitas, keterampilan serta bakat individu untuk menciptakan nilai ekonomi serta lapangan pekerjaan dengan menghasilkan dan mengeksploitasi daya kreasi dan daya cipta individu tersebut. Industri kreatif dipandang semakin penting dalam mendukung kesejahteraan dalam perekonomian bangsa. Melihat lebih dalam pada kinerja ekspor industri fesyen dan kerajinan, ekspor industri fesyen mencapai Rp.76,7 triliun atau meningkat 8 persen pada tahun 2016. Sejalan dengan fesyen, pada industri kerajinan pun terdapat peningkatan kinerja ekspor yakni mencapai Rp.21,7 triliun atau meningkat 7,6 persen dibandingkan tahun sebelumnya [5]. Untuk meningkatkan pencapaian tersebut dalam mendukung industri kerajinan tangan, terdapat sebuah potensi dalam menghasilkan banyak kemungkinan baru dari sebuah material yang dapat dijadikan sebagai kreasi inovatif untuk menghasilkan sebuah produk kerajinan tangan. Hal ini dapat dilakukan dengan eksplorasi material untuk mendapatkan bentukan baru yang unik.

Eksplorasi material adalah salah satu pendekatan desain yang bertujuan untuk mendapatkan kemungkinankemungkinan baru dari sebuah material yang diuji dan didasarkan pada karakteristiknya. Berdasarkan karakteristik 
yang khas dimiliki oleh sebuah material, maka material tersebut akan memberikan respon balik yang khas bila diberi perlakuan. Bentukan baru dapat berupa hal yang unik dan dapat dijadikan sebuah inspirasi bagi sebuah karya desain. Beberapa hasil ekplorasi adalah sebagai berikut :

1. Eksplorasi karakteristik struktur daging dan kulit bambu.

Bambu secara umum memiliki struktur kulit ari dalam, daging, dan kulit keras bagian luar. Struktur ini membentuk kekuatan bambu untuk memperoleh kondisi yang lurus. Kondisi khas dari bambu, seperti juga beberapa bahan serat lain adalah terdapatnya dua kondisi yang berbeda, yaitu kondisi basah dan kondisi kering. Dengan memanfaatkan dua keadaan ini, akan dapat dihasilkan satu teknik pengolahan yang mampu menghasilkan gagasan bentuk yang unik.

2. Eksplorasi bagian daging bambu.

Ketebalan daging bambu merupakan struktur yang membentuk lengkungan bambu dengan diameter tertentu. Dengan menipiskan bagian daging bambu hingga pada ukuran tertentu, kondisi bambu yang sebelumnya melingkar, dapat diubah menjadi lembaran [6].

3. Eksplorasi kulit bambu.

Kulit luar bambu memiliki karateristik yang unik. Memiliki kekerasan bersifat searah dengan serat bambu, akan tetapi tidak rekat dengan kuat secara tegak lurus. Dengan memotongnya searah dengan serat, akan diperoleh ketebalan minimum yang menghasilkan lengkungan yang menarik [6].

\section{METODE PENELITIAN}

\section{A. Studi Literatur}

Mengumpulkan data yang digunakan sebagai data sekunder yang diambil dari jurnal, buku, dan lain-lain untuk menunjang riset desain yang dilakukan. Adapun hasil yang didapat dari literatur terkait komparasi jenis-jenis material bambu dan pemanfaatannya yang diambil dari jurnal Keberadaan Material Bambu sebagai Subtitusi Material Kayu pada Penerapan Desain Interior dan Arsitektur, oleh Hartanti, Humaniora, 1 (1), 11-19. Serta literatur terkait pendekatan eksplorasi material dari prinsip teknologi pengolahan bambu.

\section{B. Observasi}

Mengumpulkan data dengan observasi variable-variabel yang dibutuhkan dengan cara mengamati, mendokumentasi dan menyimpulkan hasilnya. Metode ini diperlukan untuk melihat aktivitas dari pengrajin terkait dari teknik pengolahan bambu yang digunakan. Observasi dilakukan di Workshop Bambu, Selaawi, Jawa Barat pada tanggal 29-30 Januari 2018 dengan Utang Mamad selaku pengrajin bambu.

\section{C.Persona}

Persona menggambarkan pola perilaku dasar individu menjadi bentuk representatif yang bertujuan untuk menemukan fokus desain, dan skenario dalam wawancara. Teknik persona digunakan untuk menentukan karakteristik pengguna sesuai dengan produk yang dimaksud. Hasil metode ini mendeskripsikan jenis material lain yang akan dikombinasikan dengan material bambu, kombinasi ragam bambu dan lain-lain berdasarkan data yang telah dikumpulkan sehingga membawa ke arah fokus desain.

\section{Eksperimen}

Metode pengumpulan data yang didapatkan melalui uji coba yang dilakukan oleh penulis untuk mengeksplorasi material bambu menggunakan teknik-teknik pengolahan pada bambu. Mengeksplorasi material bambu dengan beraneka ragam perlakuan terhadap material, seperti mengidentifikasi karateristik material, eksplorasi proses pembentukan, analisis kombinasi dengan material lain joining dan eksplorasi pewarnaan serta finishing. Sehingga dapat memahami karateristik material agar mendapat tampilan visual serta fungsi yang paling optimal.

\section{HASIL DAN PEMBAHASAN}

\section{Analisis Karateristik Material Bambu}

Dari hasil observasi selama 3 hari di Workshop bambu di Selaawi, Garut dan melihat secara langsung dan intens proses pengolahan material bambu maka diperoleh informasi mengenai karakter material bambu sebagai berikut:

Tabel 1.

Karakter Material Bambu

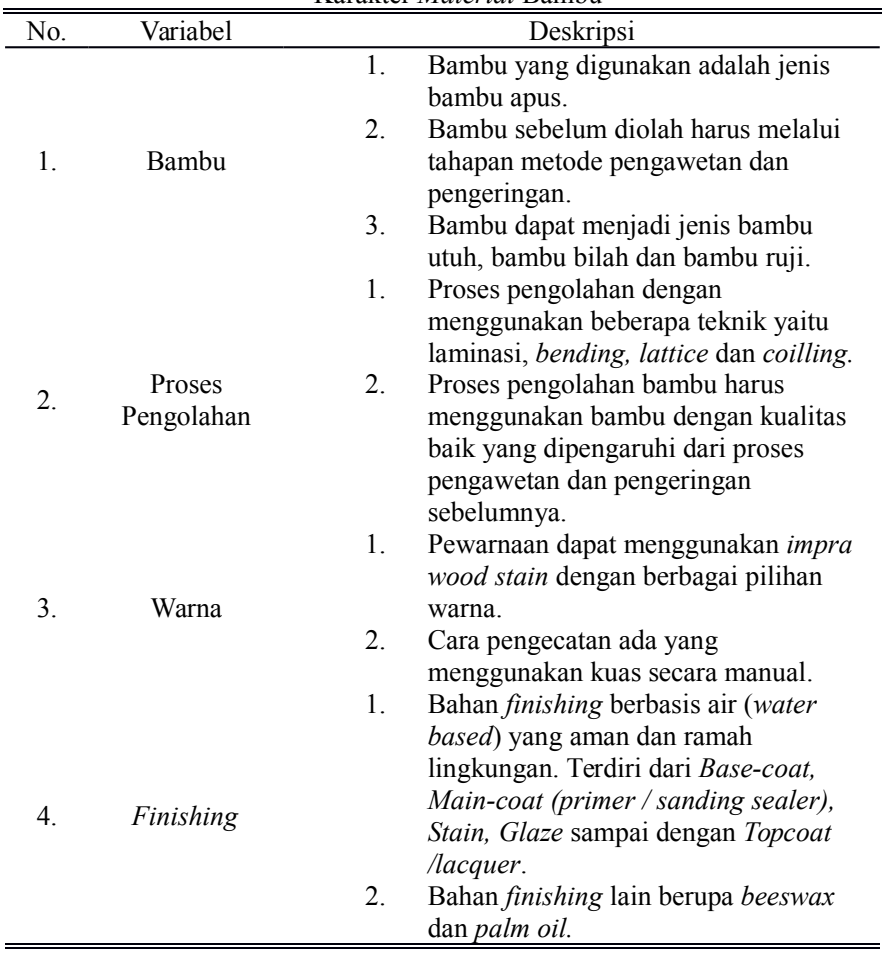

\section{Teknik Membuat Ragam Material Bambu}

1) Eksplorasi Kombinasi Teknik Coiling dan Lattice

Teknik pengolahan bambu yang sering digunakan untuk proses pembuatan produk dari kerajinan bambu salah satunya yaitu teknik coiling. Teknik coiling yaitu proses melilitkan dapat dilakukan dengan proses melingkar dan dilakukan dari arah kiri ke kanan.

Dalam proses pengolahan bambu dalam membentuk suatu produk, tidak dibatasi oleh satu teknik pengolahan. Satu produk dapat terdiri dari beberapa teknik pengolahan bambu yang dapat dikombinasikan. Dalam eksperimental ini, penulis mencoba mencari beberapa bentuk eksplorasi dari kombinasi teknik lattice dengan coiling.

Bambu yang telah diberi perlakuan pengawetan, diolah menjadi bentuk bilah dengan lebar 2-2,5 cm dengan ketebalan 
0,5 mm. Kemudian dipecah pada seluruh permukaan kulit dengan alat berupa tang agar mudah dibentuk. Prosesnya dilakukan dengan arah patahan dari kiri ke ujung kanan bambu.

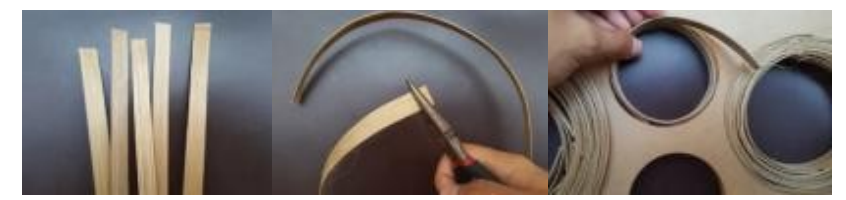

Gambar 1. Proses pertama teknik melingkar bambu menggunakan alat konvensional.

Bambu yang patah lebih mudah dibentuk sesuai dengan kebutuhan. Dalam hal ini bambu dibentuk dengan cetakan bulat menggunakan cetakan akrilik dengan dimensi yang diinginkan. Kemudian dilem menggunakan lem $G$ yang setelah itu dilapisi dengan cairan lem putih dengan air. Fungsi memberi cairan lem ini untuk merekatkan bambu. Kemudian bambu dikeringkan selama \pm 2 jam. Setelah bambu dikeringkan, permukaan gulungan bambu diratakan dengan bantuan mesin amplas untuk mendapatkan permukaan bambu yang rapi dan halus.

Proses selanjutnya adalah menempatkan dempul dari campuran lem putih dengan serbuk kayu atau bambu, untuk menutup lubang-lubang pada bambu yang melilit.

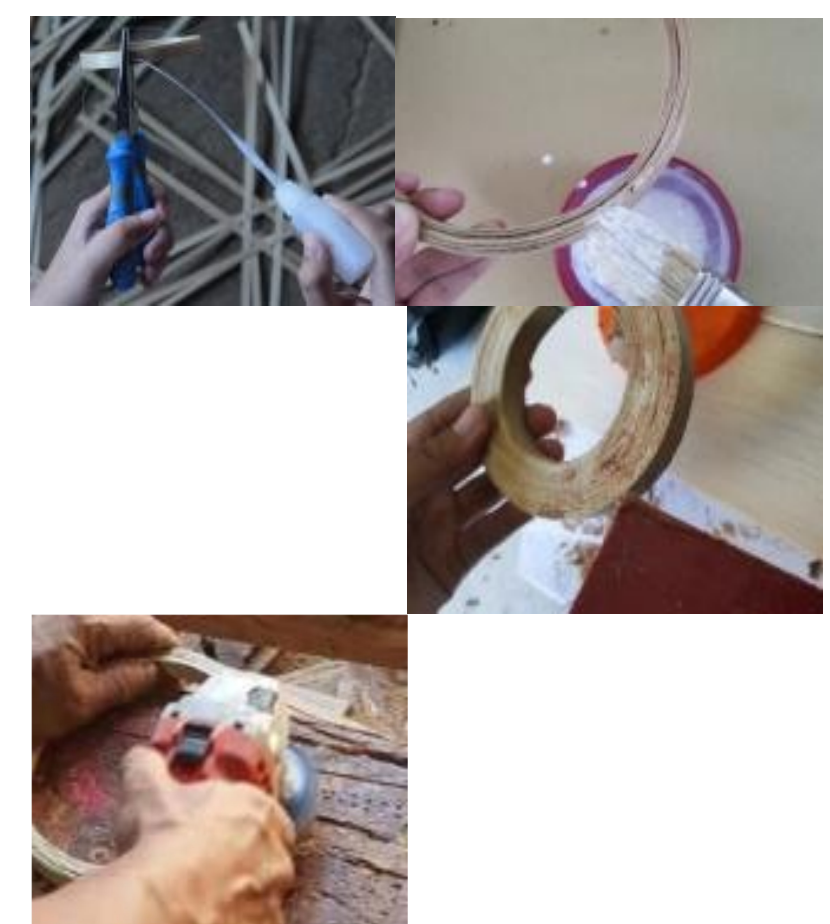

Gambar 2. Proses perekatan dan pengamplasan menggunakan bantuan alat dan proses manual.

Pada eksperimen ini dicari beberapa eksplorasi bentuk dari kombinasi pada teknik coiling dengan teknik lattice. Teknik lattice yaitu proses serut bambu untuk mengecilkan tebal bambu agar ujung bambu mengecil dan pas dengan diameter pada alat bantu tradisional pembentuk ruji. Ruji ini dapat di bending sesuai dengan bentuk yang diinginkan dan di kombinasikan pada bambu coiling.
Dari proses pembuatan teknik melingkar bambu, ada beberapa bentuk eksplorasi yang bisa dikombinasikan dengan teknik ruji bambu. Berikut ini adalah beberapa hasil eksperimen dalam bentuk kombinasi teknik melingkar dan ruji:

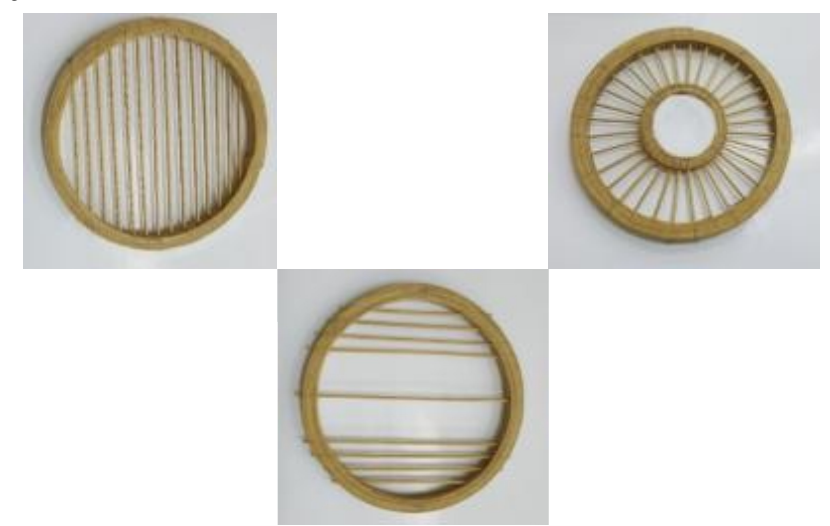

Gambar 3. Kombinasi teknik melingkar bambu eksperimental.

Dari beberapa percobaan alternatif, uji kombinasi dan bentuk kombinasi dua teknik pengolahan bambu, yaitu teknik melingkar bambu dengan bambu ruji, diperoleh beberapa arah pengujian yang dapat diklasifikasikan, yaitu:

1. Arah bambu lattice vertikal kerapatan rapat.

2. Arah bambu lattice horizontal kerapatan renggang-rapat.

3. Arah bambu lattice point to center secara melingkar.

Dilakukan juga eksperimen eksplorasi dalam kombinasi anyaman yaitu; system anyam dihubungkan antara ruji bambu.

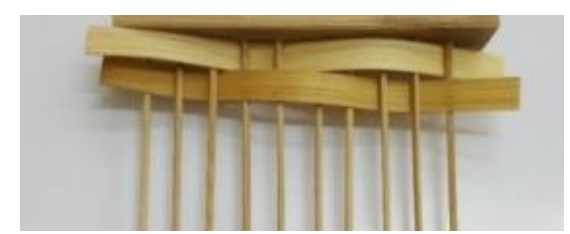

Gambar 4. Gulungan bambu yang dikombinasikan dengan bambu ruji pada bagian tengah diisi dengan anyaman bambu.

Untuk eksperimen dengan jenis ragam lain, dibuat suatu studi model yang menggunakan desain alternatif yang telah dibuat. Pembuatan model studi dilakukan dengan bahan pengganti yaitu bahan duplex dan menggunakan bahan pendukung asli dari bambu ruji. Pemodelan dilakukan pada skala 1: 1 .

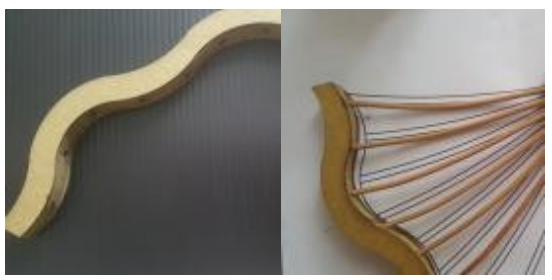

Gambar 5. Proses pembuatan studi model ragam bentuk.

Kemudian dari studi model yang dibuat dilakukan percobaan langsung dengan material bambu dengan teknik bending bambu menggunakan mal sesuai bentuk yang telah dirancang. 


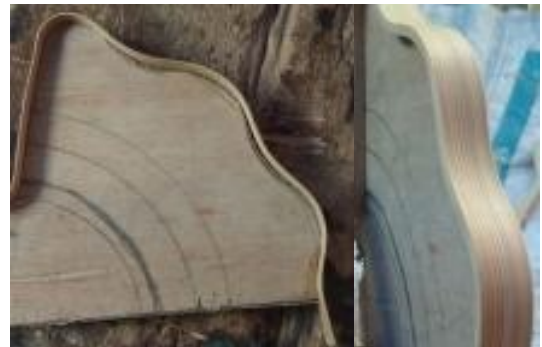

Gambar 6. Proses bending bambu mengikuti mal.

Setelah jadi rangka luar yang dibentuk dengan mal yang sudah sesuai dengan dimensi rancangan desain, kemudian rangka bambu di lubangi sesuai jarak yang telah ditentukan untuk jalur masuk dari bambu ruji.

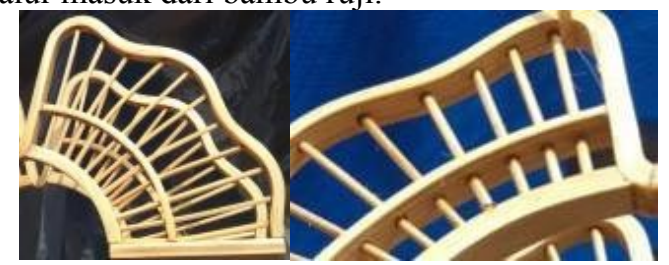

Gambar 7. Hasil penggabungan dari jenis teknik bambu bending dengan bambu ruji.

\section{2) Eksplorasi Finishing dengan Cara Pewarnaan}

Eksperimen selanjutnya adalah eksplorasi warna dalam desain ini menggunakan pewarna alami yang diterapkan pada bilah bambu. Langkah-langkahnya adalah menyiapkan alat material, membuat sampel bilah bambu dengan ukuran $2,5 \mathrm{~cm}$ x $15 \mathrm{~cm}$, celupkan ke dalam setiap warna, celupkan ke dalam larutan fiksasi, lalu catat hasil warna dan dokumentasikan.

Eksperimen pertama adalah eksplorasi pewarnaan alam. Teknik pewarnaan terdiri dari empat warna. Proses pewarnaan dalam pewarnaan ini berlangsung selama 8 jam. Setiap jenis pewarnaan alami akan dikunci menggunakan fiksasi. Ada dua jenis fiksasi yang digunakan, yaitu tawas dan tunjung. Setiap fiksasi menghasilkan warna yang berbeda. Fiksasi tawas menghasilkan warna yang lebih cerah dan fiksasi tunjung menghasilkan warna yang lebih gelap.

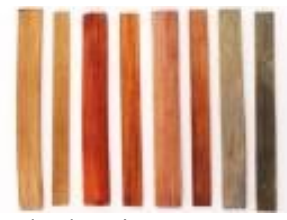

Gambar 8. Hasil pertama eksplorasi pewarnaan alami menggunakan fiksasi tawas.

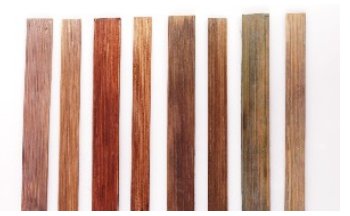

Gambar 9. Hasil kedua eksplorasi pewarnaan alami menggunakan fiksasi tunjung.

Eksplorasi kedua dalam pewarnaan menggunakan pewarna buatan. Pewarnaan buatan pertama menggunakan pewarna dari Wantex. Eksplorasi dilakukan dengan menggunakan tiga pilihan warna yaitu cabai merah, kuning dan biru. Proses pewarnaan selama 1 jam. Hasil pewarnaan dengan Wantex adalah warna yang lebih cerah dan lebih tajam.
Gambar 10. Ketiga hasil eksplorasi pewarna buatan menggunakan wantex.

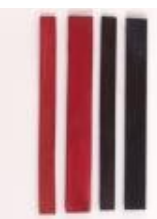

Gambar 11. Keempat hasil eksplorasi pewarna buatan menggunakan remasol.

Tabel 2.

Eksplorasi Treatment Finishing

Jenis Finishing Hasil Treatment

$\underset{1}{\text { Eksperimen }}$

Deskripsi Olive oil Hasil pada permukaan bersih,

Eksperimen

2 transparan dan halus

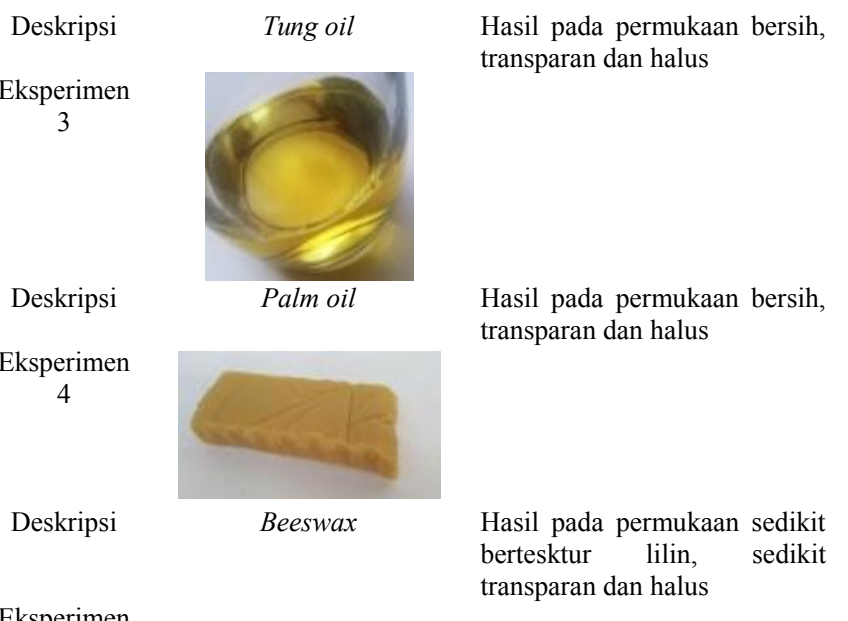

Eksperimen
Deskripsi Melamine (Clear Dof) Hasil pada permukaan lapisan mengkilap dan halus

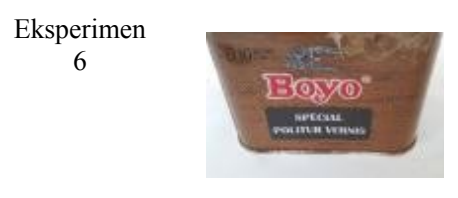

Deskripsi Wood Stain
Hasil pada r permukaan
meninggalkan warna
transparan sesuai 


\begin{tabular}{cll}
$\begin{array}{c}\text { Eksperimen } \\
7\end{array}$ & wood stain \\
& & \\
Deskripsi $\quad$ Pylox (Finishing Dof) & $\begin{array}{l}\text { Hasil pada permukaan } \\
\text { transparan tetapi menutupi } \\
\text { permukaan bambu dengan } \\
\text { lapisan finishing dof }\end{array}$ \\
\hline \hline
\end{tabular}

Eksplorasi ketiga jenis pewarna buatan lainnya menggunakan remasol. Pewarnaan dipilih dengan dua jenis warna yaitu merah dan biru. Proses pewarnaan dengan remasol selama 12 jam. Hasil pewarnaan remasol menghasilkan warna yang kuat tetapi tidak terlalu cerah.

Dari percobaan di atas terdapat proses pewarnaan pada bilah bambu yang menghasilkan berbagai warna, baik dengan menggunakan pewarna alami atau buatan, yang nantinya akan dijadikan referensi dalam memilih konsep warna pada setiap rangkaian produk.

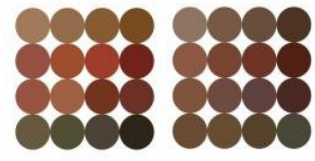

(a)

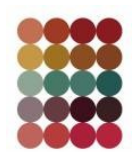

(b)
Gambar 12. Hasil eksplorasi finisihing dengan cara pewarnaan menghasilkan palet warna a) pewarna alami dan b) pewarna buatan.

\section{3) Eksplorasi Finishing Natural}

Eksplorasi eksperimen finishing natural pada material bambu juga dilakukan dengan beberapa pemberian treatment finishing pada permukaan produk bambu. Hasil eksperimen secara lengkap dapat dilihat pada Table 2 .

Dari eksperimen treatment finishing pada bambu didapatkan dua kelompok finishing dengan jenis finishing yaitu Open Pore Finishing dengan jenis finishing yang tidak menutupi pori-pori dari permukaan bambu. Jenis finishing yang termasuk dalam kategori kelompok ini yaitu olive oil, palm oil, tung oil dan beeswax. Kemudian jenis Close Pore Finishing dengan jenis finishing yang menutupi pori-pori dari permukaan bambu. Jenis finishing yang termasuk dalam kategori kelompok ini yaitu pylox, melamine dan wood stain.

4) Eksplorasi Joining

Eksplorasi lebih lanjut adalah alternatif untuk menggabungkan bambu dengan kombinasi bahan lain yang dapat berupa kain atau kulit. Eksplorasi dilakukan dengan melubangi bambu untuk mengakses benang jahit menggunakan bor.

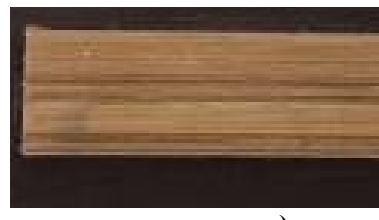

a)

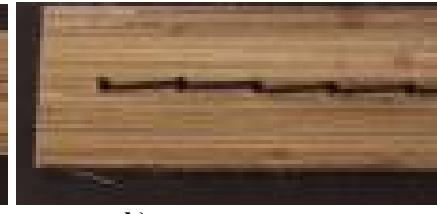

b)
Gambar 10. Hasil eksplorasi joining dengan a) lem dengan teknik capit dan b) teknik tusuk jahit jelujur.

Proses joining yang dilakukan menggunakan benang, potongan kulit, dan potongan material bambu dengan jenis laminasi. Proses dilakukan dengan melubangi permukaan material bambu dengan bor sebagai jalur masuknya benang saat ditisik. Sebelum dijahit, permukaan potongan material bambu dilem terlebih dahulu pada permukaan potongan kulit.

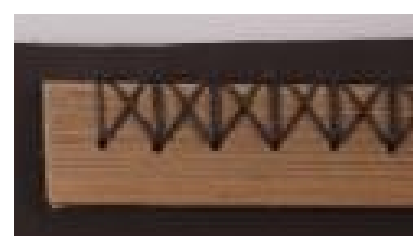

a)

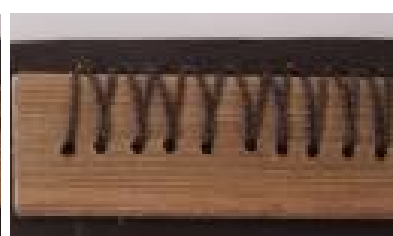

b)
Gambar 13. Hasil eksplorasi joining dengan a) teknik tusuk jahit silang dan b) teknik tusuk jahit jeruji.

\section{KESIMPULAN}

Dalam perancangan ini, karakter yang ingin diekspos adalah karakter teknik pengolahan material bambu yang unik, keberagaman eksperimen bentuk, serta pewarnaan dan finishing, karena akan digunakan sebagai material pembuatan produk apparel jenis tas.

a) Berdasarkan analisis karateristik material yang didapat dari hasil observasi yaitu material bambu memiliki berbagai macam karakter yang dipengaruhi oleh jenis bambu, proses awal pengolahan bambu, hingga proses pengolahan lanjutan.

b) Berdasarkan analisis pengolahan material bambu didapatkan hasil bahwa proses pengolahan bambu dalam membentuk suatu produk, tidak dibatasi oleh satu teknik pengolahan saja. Proses pengolahan bambu memiliki fleksibilitas (bilah, ruji, coiling dan sebagainya).

c) Dari eksperimen pewarnaan diatas didapat hasil untuk proses pewarnaan pada bilah bambu yang menghasilkan berbagai macam warna, baik dengan menggunakan pewarna alami maupun buatan, yang nantinya akan dijadikan acuan dalam pemilihan konsep warna di setiap serial produk.

d) Dari eksperimen treatment finishing pada bambu didapatkan dua kelompok finishing dengan jenis open pore finishing dan close pore finishing.

e) Berdasarkan dari beberapa eksplorasi joining antara bambu dan material kombinasi dengan kulit yang telah dilakukan, didapatkan dua kelompok teknik penyabungan, yaitu mengunakan benang dan menggunakan lem.

\section{UCAPAN TERIMA KASIH}

Terima kasih disampaikan kepada Pak Utang, selaku mitra yang telah memberikan bantuan dalam pengumpulan data selama proses survey di workshop, sehingga penulis dapat menjalani Studi dengan lancar.

\section{DAFTAR PUSTAKA}

R. Batubara, "Pemanfaatan Bambu di Indonesia," 2002.

I. K. Widnyana, M. Budiasa, and P. Sujana, "Pemberdayaan pengerajin furniture bambu dalam usaha peningkatan jumlah serta mutu ekspor kerajinan bambu di Kabupaten Gianyar Bali," J. Ngayah, vol. 1, no. 1, 2010. 
[3] M. Liebl and T. Roy, "Handmade in India: Preliminary analysis of crafts producers and crafts production," Econ. Polit. Wkly., pp. 5366-5376, 2003.

[4] Kasmudjo, S. Sunarta, and T. B. Widowati, "Pengaruh Beberapa Jenis Bambu Pada Umur Yang Berbeda Sebagai Bahan Mebel dan Kerajinan," 2012.
[5] T. Bambang, B. Mardiono, K. Hertina, T. Ari, and A. A. Weny, "Pengembangan Desain Produk Berbahan Pelepah Pisang Untuk Meningkatkan Daya Saing Usaha Kecil," J. Desain IDEA, vol. 17, no. 1, pp. 1-4, 2018.

$[6]$

A. Anas, Menggali Potensi Estetik Bambu Melalui Pendekatan Eksplorasi. 2012. 